\begin{tabular}{|c|c|c|c|}
\hline DE & \multirow{3}{*}{$\begin{array}{l}\text { DE GRUYTER } \\
\text { OPEN }\end{array}$} & $\begin{array}{l}\text { HUNGARIAN JOURNAL OF } \\
\text { INDUSTRY AND CHEMISTRY }\end{array}$ & \multirow[t]{3}{*}{ 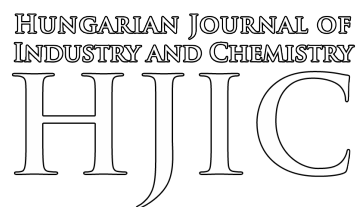 } \\
\hline & & Vol. 43(1) pp. 1-5 (2015) & \\
\hline & & $\begin{array}{l}\text { hjic.mk.uni-pannon.hu } \\
\text { DOI: } 10.1515 / \text { hjic-2015-0001 }\end{array}$ & \\
\hline
\end{tabular}

\title{
HEAVY METAL BALANCE IN A COMMUNAL WASTEWATER TREATMENT PLANT
}

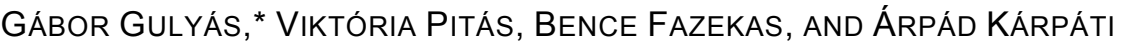 \\ Department of Environmental Engineering, University of Pannonia, Egyetem u. 10, 8200 Veszprém, \\ HUNGARY
}

\begin{abstract}
Heavy metal removal from a municipal wastewater treatment plant was evaluated in the given study. The aim of the work was to find water or sludge streams in the technology that could be treated separately for heavy metal removal to maximise the efficiency of the entire treatment. The results proved that in the plant studied $70-80 \%$ of the metal content was discharged. Only $5-20 \%$ was retained in the digested sludge. A small percentage of the metal content of the influent could only be measured in the primary and secondary sludges. Otherwise, there were very similar metal concentrations in these sludge streams. The reject water exhibited an inconsiderable level of metal recycling in the technology, no more than $2-3 \%$ of the influent load. Some $2-10 \%$ of the heavy metal content of the inlet was removed from the sand trap. We did not find the separate heavy metal removal from the sludge streams efficient as most of the heavy metal load finally was discharged from the treatment plant with the treated effluent into the recipient.
\end{abstract}

Keywords: activated sludge, heavy metals, mass balance, municipal wastewater

\section{Introduction}

Industrial discharges into municipal wastewaters from metal refining and other industrial sources are hazardous with regard to purification process due to their heavy metal contents. That is why nowadays heavy metal removal from these discharges at the site of the waste production is strictly regulated. The next possibility for removing heavy metals from wastewater is the activated sludge process of the Publicly Owned Treatment Works (POTWs) [1]. The mechanism of heavy metal removal in the activated sludge process is not completely understood yet [2]. Even the inhibition effects of some metals for specific microorganisms are not properly known. That is why our study tried to summarise the heavy metal removal of an activated sludge plant on the basis of its detailed mass balance. We excluded from this study the influence of any technological parameters like oxygen supply, $\mathrm{pH}$, sludge age, complexing agents, etc. or the microbial composition of the working biomass [2-3].

An overview of the possibility of the removal of metals from sludges of sewage treatment plants has already been presented [2,4]. Rather different removal efficiencies were published from many measurements all over the world. These studies concluded that around $70 \%$ of the $\mathrm{Mn}$ and $\mathrm{Cu}$ load can be accumulated in the activated sludge, while 50-60\% of the $\mathrm{Cr}, \mathrm{Cd}, \mathrm{Pb}, \mathrm{Fe}, \mathrm{Ni}$, and $\mathrm{Zn}$ will leave the plant as it is discharged into the recipient with the treated

*Correspondence: gulyasg@almos.uni-pannon.hu effluent. It is well known, that some special forms of these heavy metals in the sludge or activated sludge process are more critical than their total concentrations $[5]$.

In our study, we measured the heavy metal concentrations in the different liquid and sludge streams of a Hungarian wastewater treatment unit in Veszprém treating municipal effluent relatively free of industrial metal discharges. We calculated a total mass balance for the plant and evaluated the feasibility of the separate removal of some metal contaminants from the sludge residue to produce more valuable agricultural soil amendment.

\section{Materials and Method}

The studied activated sludge process treats daily 13,000 $\mathrm{m}^{3}$ of sewage, while its nominal daily capacity of $21,000 \mathrm{~m}^{3}$ shows considerable underutilisation. It has a proper digestion capacity for the primary and secondary sludge of the main stream. We considered that it is important to measure the heavy metal concentrations at the inflow and in purified effluent in some mixed liquid streams and the final dried sludge as well. From the material balance established from these data, it seemed possible to decide about the reality of the use of some separate heavy metal removal steps in the treatment line.

To establish a heavy metal mass balance, we took samples several times from the liquid, mixed sludge and dried sludge as well. The sampling points in the technology can be seen in Fig.1. 


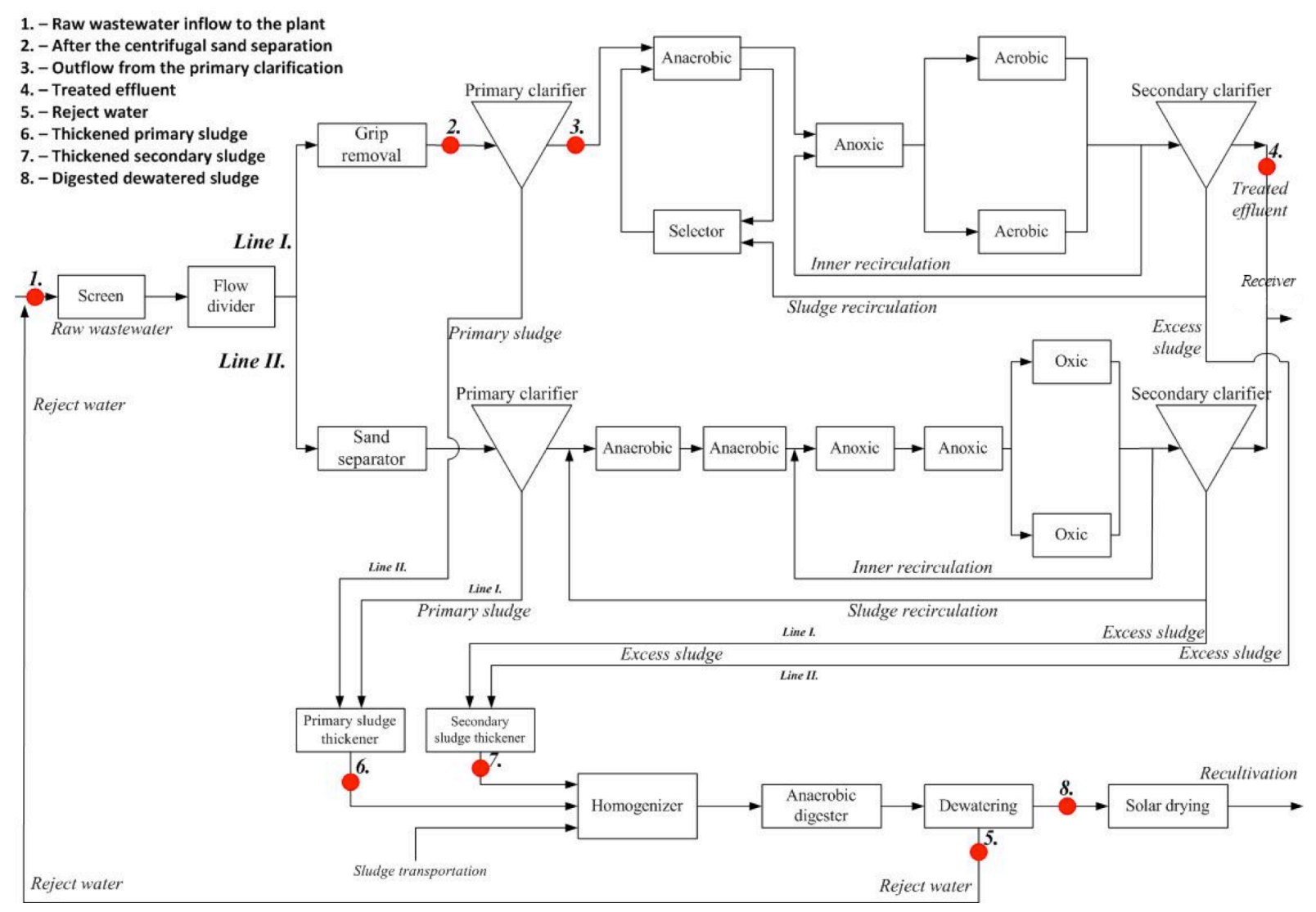

Figure 1. The technology and sampling points for checking heavy metal concentrations.

Samples 1 to 4 were collected during the day every other hour. Samples 5-8 were collected when sludge pumping or drying was in operation. These were homogenised, cooled, and stored as prescribed by Hungarian Standard MSZ 318-2:1985 protocol.

The dissolution of the metal content was followed by the atomic absorption spectrophotometric measurement for eight $(\mathrm{Cd}, \mathrm{Co}, \mathrm{Mn}, \mathrm{Ni}, \mathrm{Cr}, \mathrm{Cu}, \mathrm{Fe}$, and $\mathrm{Pb})$ metal contaminants. From these data, the metal content of the sludge phases was determined for the suspended (SS) and total solid (TS) contents for Samples 5-8. It was assumed that the dissolved heavy metal content of the liquid phase equals to that of the treated effluent in Samples 6 and 7 and with that of the reject water in Sample 8.

For measuring SS and TS contents of the sludge containing samples (No. 6-8), we used the Hungarian Standard MSZ 260/3-73 standardised method. The average daily amount of the reject water had to be calculated for the calculation of the material balance from these measured values, as the flow was not measured in the plant.

Dissolution of the metals from the different samples was carried out by a Mars 6 microwave digester. The temperature program of the digester was optimised in a preliminary study [6]. For the addition of chemicals for digestion, we followed the recommendation of Hungarian Standard MSZ 1484-3 protocol (Chapter 4.2.2.3). Before digestion, $3 \mathrm{ml}$ of $68 \% \mathrm{HNO}_{3}$ and $9 \mathrm{~cm}^{3}$ of concentrated $\mathrm{HCl}$ was given to every $0.5 \mathrm{~cm}^{3}$ sample. The microwave digestion of the sludge samples was carried out according to the same heating program for all samples. After $20 \mathrm{~min}$ of heating, digestion was completed in $10 \mathrm{~min}$ at $180{ }^{\circ} \mathrm{C}$. After digestion and dilution, the heavy metal concentrations were measured by a Thermo Scientific ICE 3000 Atomic Adsorption Spectrophotometer.

\section{Results and Discussion}

During the control study, the samples were taken over three one week-long periods. We measured the weekly homogenised samples stored in a refrigerator a week later than sampling in triplicates. The average metal contents for the entire measurement period are shown in Table 1.

As shown in Table 1, there was no $\mathrm{Pb}$ detected in the influents of the wastewater treatment plant. The $\mathrm{Cd}$ concentration was low $\left(0.03 \mathrm{mg} \mathrm{dm}^{-3}\right)$. Mn and Ni levels were a bit higher within the range of $0.08-0.15 \mathrm{mg} \mathrm{dm}^{-3}$. Co exhibited a slightly higher concentration $(0.1-0.3$ $\mathrm{mg} \mathrm{dm}^{-3}$ ) than $\mathrm{Mn}$ and $\mathrm{Ni}$. The $\mathrm{Cu}$ content was constant at around $0.2 \mathrm{mg} \mathrm{dm}^{-3}$. These values are as expected from our earlier measurements at this plant. The Fe had the highest concentration in the inflow (up to $356 \mathrm{mg}$ $\mathrm{dm}^{-3}$ ) and it remained similarly high relative to the other metal contaminants in the outflow from the plant.

To calculate the heavy metal mass balance in the process, the flow rates and sludge production had to be taken into account. As the hydraulic retention time (HRT) in the plant was more than one day and the sludge age was nearly 20 days, we used average 
Table 1. The total heavy metal concentrations $\left(\mathrm{mg} \mathrm{dm}^{-3}\right)$ of the liquid and sludge-containing streams of the activated sludge process (variation in concentrations is in the order of $\pm 31 \%$ ).

\begin{tabular}{lllllllll}
\hline samples & $\mathrm{Cd}$ & $\mathrm{Co}$ & $\mathrm{Mn}$ & $\mathrm{Ni}$ & $\mathrm{Cr}$ & $\mathrm{Cu}$ & $\mathrm{Fe}$ & $\mathrm{Pb}$ \\
\hline raw wastewater & 0.023 & 0.169 & 0.123 & 0.123 & 0.185 & 0.231 & 7.938 & $<0.001$ \\
after grit removal & 0.023 & 0.166 & 0.105 & 0.120 & 0.174 & 0.223 & 7.819 & $<0.001$ \\
primary clarified wastewater & 0.022 & 0.161 & 0.094 & 0.109 & 0.168 & 0.214 & 7.168 & $<0.001$ \\
treated effluent & 0.021 & 0.152 & 0.062 & 0.107 & 0.161 & 0.202 & 0.079 & $<0.001$ \\
reject water & 0.005 & 0.128 & 0.093 & 0.048 & 0.160 & 0.095 & 10.147 & $<0.001$ \\
thickened primary sludge & 0.021 & 0.462 & 1.973 & 0.414 & 0.565 & 0.750 & 58.509 & $<0.001$ \\
thickened secondary sludge & 0.019 & 0.673 & 2.709 & 0.633 & 0.696 & 1.030 & 355.813 & $<0.001$ \\
\hline
\end{tabular}

Table 2. The main technological parameters (volumes are in $\mathrm{m}^{3}$, solid content in mass percent) used to calculate heavy metal mass-balances (variation in flow rates is in the order of $\pm 22 \%$ ).

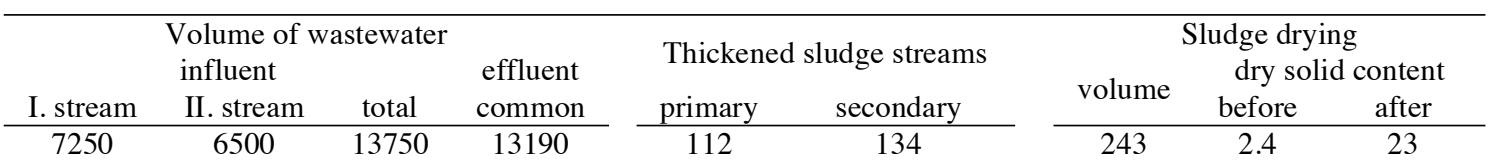

Table 3. Daily heavy metal mass (in grams per day) in the streams shown in Figure 1.

\begin{tabular}{lccccccr}
\hline samples & $\mathrm{Cd}$ & $\mathrm{Co}$ & $\mathrm{Mn}$ & $\mathrm{Ni}$ & $\mathrm{Cr}$ & $\mathrm{Cu}$ & $\mathrm{Fe}$ \\
\hline raw wastewater & 150 & 1,100 & 800 & 800 & 1,200 & 1,500 & 51,600 \\
after grip removal & 149 & 1,080 & 682 & 778 & 1,132 & 1,448 & 50,826 \\
primary clarified wastewater & 144 & 1,048 & 614 & 706 & 1,093 & 1,388 & 46,595 \\
treated effluent & 139 & 991 & 400 & 697 & 1,049 & 1,310 & 516 \\
reject water & 1.6 & 38.5 & 28 & 14.4 & 48 & 28.5 & 3,044 \\
thickened primary sludge & 2.4 & 51.7 & 221 & 46.4 & 63.3 & 84 & 6,553 \\
thickened secondary sludge & 1.5 & 42.9 & 170 & 52.8 & 78 & 82.5 & 44,170 \\
digested dried sludge & 2.5 & 90.2 & 363 & 84.8 & 93.3 & 138 & 47,679 \\
\hline
\end{tabular}

Table 4. Relative quantity of the heavy metals in streams measured as mass percentage of the influent concentrations in raw wastewater $(100 \%)$

\begin{tabular}{llcccccc}
\hline samples & $\mathrm{Cd}$ & $\mathrm{Co}$ & $\mathrm{Mn}$ & $\mathrm{Ni}$ & $\mathrm{Cr}$ & $\mathrm{Cu}$ & $\mathrm{Fe}$ \\
\hline after grit removal & 99 & 98.1 & 85.2 & 97.2 & 94.3 & 96.5 & 98.5 \\
primary clarified wastewater & 96.2 & 95.2 & 76.7 & 88.3 & 91.1 & 92.5 & 90.3 \\
treated effluent & 92.5 & 90.1 & 50 & 87.1 & 87.4 & 87.3 & 1 \\
reject water & 1.3 & 3.5 & 3.5 & 1.8 & 4 & 1.9 & 5.9 \\
thickened primary sludge & 1.6 & 4.7 & 37.6 & 5.8 & 5.3 & 5.6 & 12.7 \\
thickened secondary sludge & 1 & 3.9 & 31.3 & 6.6 & 6.5 & 5.5 & 85.6 \\
\hline
\end{tabular}

numbers for the calculation of the balance. The same was used for the primary and secondary sludge streams, as their removal was not continuous, but the material we examined had been properly homogenised. The average daily values for the streams are summarised in Table 2.

Some parameters required for the calculation were not measured at the plant. The average daily quantity of the reject water was calculated from the SS concentration of the digested sludge stream entering the drying centrifuge and that of the dried digested sludge. The quantity of the dried digested sludge was calculated from the volume of the sludge transported from the centrifuges to the solar drying part of the plant and its average dry solid content determined. This resulted in negligible errors (less than $0.1 \mathrm{~g} / \mathrm{g}$ ) since the dissolved material content of the sludge water or reject water was low enough.

Flows were calculated (Table 3) using the concentrations and daily flows of heavy metals in these sewage and mixed liquids (Tables 1 and 2). In the sewage entering the plant, the concentration of the different heavy metals did not change considerably. As a result, their mass stream had to change according to the volumetric load of the plant. This was not true for the sludge streams, as the plant had a great equalisation for the total sludge mass.

From Tables 1 and 3 , it can be seen that the concentrations of the measured heavy metals did not change or decrease significantly in the sewage streams or even in the treated effluent. At the same time, the sludge containing streams containing around 1 and $3-4 \%$ dry material showed much higher heavy metal levels. Heavy metals removed from the influent (dissolved and solid) were expected to concentrate in the sludge phase of these streams and in the dried sludge as well. This means that the removal of heavy metals in this treatment facility was very poor. We hypothesise that the low specific organic material load (estimated daily value of $0.2 \mathrm{~g}$ KOI per g MLSS) and the high sludge age (more than 20 days) may result in the dissolution of the heavy metals into the liquid phase.

From data in Table 1, the leftover heavy metal content of the different streams can be calculated. The results are shown in Table 4. According to the results, $\mathrm{Cd}$ was not removed from the sewage by the activated 


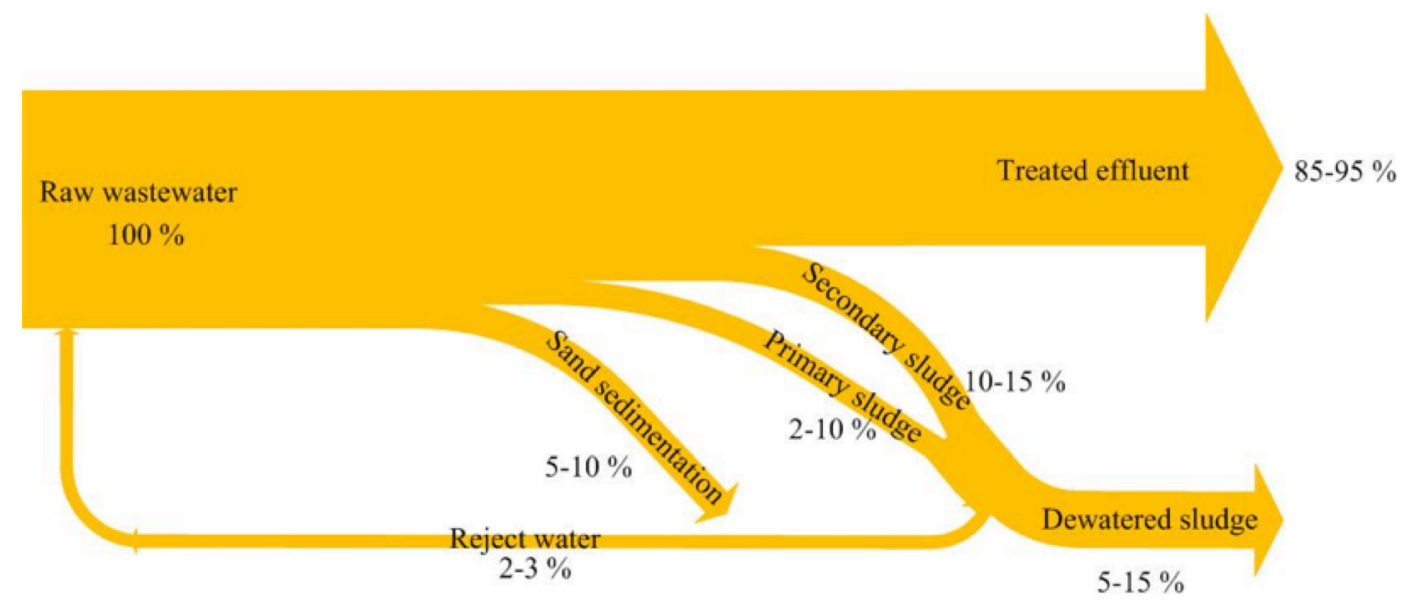

Figure 2. Removal of the heavy metals in the activated sludge of a Publicly Owned Treatment Works

(percentages indicate the average daily quantities relative to the inflow values for the studied metal except $\mathrm{Fe}$ ).

sludge process. It was absent in the reject water of the plant and only $1.0+1.6 \%$ of the Cd load was adsorbed in the final sludge produced. The load of $\mathrm{Co}, \mathrm{Mn}, \mathrm{Ni}$ and $\mathrm{Cu}$ was one order of magnitude bigger within a narrow daily load range (800-1,600 g per day). A significant portion of all these metals left the plant with the treated effluent. No more than $4-5 \%$ of the Co remained in the dried sludge according to our measurements and only $1-3 \%$ of the total load was recycled to the inlet point with the reject water. Approximately less than half of the $\mathrm{Mn}$ remained in the purified water and the rest was concentrated in the dried sludge. Around $1.5 \%$ of the Mn content of this sludge was recycled at the inlet with the centrifuge water. The metal adsorption of the primary and secondary sludge seemed to be similar, which also suggested that about three quarters of the inlet $\mathrm{Mn}$ load remained in the sewage stream after primary purification. In the case of $\mathrm{Ni}$, only $15-20 \%$ remained in the solid residue and one tenth of that was recycled at the inlet with the reject water. The $\mathrm{Ni}$ seemed to be adsorbed and present in the two types of sludge in a similar ratio. $\mathrm{Cr}$ seemed to be bound to the primary sludge while only a small portion was removed by the biological step. These two stages of the sludge processes could not remove more than $5 \%$ of the initial level. However, this removal efficiency seems to be enough, since the inlet concentration is low enough $(<$ $0.5 \mathrm{mg} \mathrm{dm}^{-3}$ ) The removal efficiency of the treatment for $\mathrm{Cu}$ seemed better than for other metals, but it was no more than 15-20\%. Most of the removed $\mathrm{Cu}$ was captured in the secondary sludge. It has been observed before that some municipal sewage sludge contains high concentrations of $\mathrm{Cu}$ due to the high $\mathrm{Cu}$ content of the raw sewage. According to the given study, Fe exhibits the highest concentration in the sewage, around 500 times greater than the other metals studied here. The Fe is oxidised in the activated sludge process and is present in the biomass as hydroxide. The removal efficiency was $99 \%$ according to the measurements.

Table 3 indicates that sand removal has practically no influence on the metal content of the sewage. In the primary purifier, metal removal is poor except for the cases of $\mathrm{Mn}$ and $\mathrm{Fe}$. Removal of metals within the secondary sludge was a bit more efficient than within the primary one. Only Mn was better adsorbed onto the biomass (around 50\%). However, Fe was almost totally removed within the sludge phase (99\% removal). Concentrations of the other metals studied decreased by only a modest $5-15 \%$.

Depending on the sludge removal from the digesters to centrifuges the average daily reject water quantity is around $200 \mathrm{~m}^{3}$. With this flow only $2-3 \%$ of the heavy metal load is recycled into the sewage stream entering the plant. This is such a small percentage that separate metal removal from that stream is not needed. However, the biggest problem of this sewage treatment facility is the poor removal of the heavy metals within the sludge. A similar average removal of heavy metal pollutants from the sewage can be seen from the inflow and treated effluent concentrations in Table 1 and the removal percentages of the metals in different processing steps in Table 4. From other investigations, we learnt that around half or a slightly greater proportion of these metals can be removed within the sludge residue. In our studies, we could not measure such high levels of removal neither in the primary nor secondary sludges. Moreover, only a small ratio of the metal content of the raw sludge can be dissolved during anaerobic digestion. According to our measurements, most of the heavy metals left the plant within the effluent.

Changes to the total heavy metal content of the different streams in the plant tested are graphically illustrated in Fig.2 for most of the metals studied here. $\mathrm{Fe}$ is an exception, as it is efficiently removed within the different sludge fractions. It cannot be dissolved even in the digester, its hydroxides and sulphides of limited solubility are strongly adsorbed by the bioproduct of the treatment. Fig.2 clearly indicates that heavy metals are recycled within the reject water in a small ratio. The dried digested sludge also removed a very small ratio of the sewage load.

\section{Conclusions}

According to our measurements in an activated sludge at a publicly owned municipal sewage treatment plant, 
the removal of heavy metals can be moderate, which is far from the removal efficiencies published by previously. A large proportion of the heavy metal content of the inflow sewage remains in the aqueous phase and leaves within the treated effluent. Only a minor ratio of approximately $5-15 \%$ is adsorbed in the sludge or taken up by the biomass produced in the treatment. The primary and secondary sludges exhibited similar heavy metal removal efficiencies except for iron, which is mainly removed by the secondary sludge. The heavy metal content of the mixed primary and secondary sludges decreased by a small extent (5-15\%) during digestion. The reject water containing the dissolved metals exhibited such low metal concentrations that treatment of it separately does not seem to be economical. It contains only $2-3 \%$ of the total heavy metal load of the plant. At the same time $80-90 \%$ of that leaves the plant within the treated effluent.

Consequently, we could not find high heavy metal concentrations in the dried digested sludge of this plant. The sludge reprocessing and reuse pose no problems in the plant with respect to heavy metal content. The low influent concentrations of the heavy metals at the same time can be correlated with the merely pure municipal effluent from the small town and its surrounding villages.

\section{Acknowledgement}

This research was financed by the Baross Gábor Project of 2009-2010 "Infrastructure of Research Development - KD_INFRA_09-SZVISZAP (Qualification of the sewage sludge of the Hungarian Publicly Owned Treatment Works for possible decrease of their heavy metal content)", Hungarian National Research and Technology Office (National Innovation Office).

\section{REFERENCES}

[1] Lester, J.N.: Significance and behaviour of heavy metals in wastewater treatment processes. I. Sewage treatment and effluent discharge, Sci. Total Environ., 1983 30, 1-4 10.1016/0048-9697(84)90340-1

[2] Karvelas, A.; Katsoyiannis, A.; Samara, C.: Occurrence and fate of heavy metals in the wastewater treatment process, Chemosphere, 2003 53, 1201-1210 10.1016/S0045-6535(03)00591-5

[3] Özbelge, T.A.; Özbelge, H.Ö.; Tursun, M.: Effects of hydraulic residence time on metal uptake by activated sludge, Chem. Engng. Proc., 2005 44, 23-32 10.1016/j.cep.2004.04.004

[4] Stephenson, T.; Jester, J.N.: Heavy metal behaviour during the activated sludge process I. Extent of soluble and insoluble metal removal, Sci. Total Environ., 1987 63, 199-214 10.1016/00489697(87)90046-5

[5] Álvarez, E.A.; Mochón, M.C.; Sánchez, J.C.J.; Rodríguez, M.T.: Heavy metal extractable forms in sludge from wastewater treatment plants, Chemosphere, 2002 47, 765-775 10.1016/S00456535(02)00021-8

[6] Gulyás, G.; Pitás, V.; Kárpáti, Á.: Measuring the heavy metal concentrations of digested dewatered sewage sludge with the help of microwave digestion, MASZESZ Newsletter, 2013 (3-4), 3-11 (in Hungarian) 


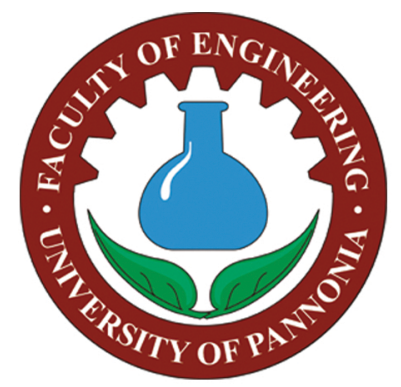

\section{Degree programmes in English at the Faculty of Engineering}

\section{Graduate Programmes}

MSc in Environmental Engineering

Duration: 4 semesters

Number of credits: 120

Tuition fee: 4500 USD/semester

Head of the programme: Dr Endre Domokos, Institute of Environmental Engineering

Contact: domokose@uni-pannon.hu

MSc in Environmental Sciences

Duration: 4 semesters

Number of credits: 120

Tuition fee: 4500 USD/semester

Head of the programme: Prof. Judit Padisak, Institute of Environmental Sciences

Contact: padisak@almos.uni-pannon.hu

BSc and MSc in Chemical Engineering

Duration: BSC 7 semesters, MSC 4 semesters

Number of credits: BSc: 210 credits MSc: 120 credit

Tuition fee: 4500 USD/semester

Head of the programme: Dr Sandor Nemeth, Institute of Chemical and Process Engineering Contact: nemeth@fmt.uni-pannon.hu

\section{Postgraduate Programmes}

Hydrocarbon Technology Development Engineer

Duration: 2 semesters

Number of credits: 60

Tuition fee: 2000 USD/semester

Head of the programme: Dr Zoltan Varga, Institute of Chemical and Process Engineering

Contact: vargaz@almos.uni-pannon.hu

Water and Wastewater Treatment System Operation

Duration: 2 semesters

Number of credits: 60

Tuition fee: 2000 USD/semester

Head of the programme: Dr Rita Szakacsne-Foldes, Institute of Environmental Sciences

Contact: foldenyi@almos.uni-pannon.hu

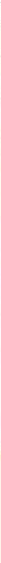

